\section{Implant Supported Overdenture: A Case Report}

\section{Abstract}

Implant supported overdentures have proved to be one of the best alternative options in prosthetic rehabilitation of various cases of edentulism. They satisfy the patient's expections, improve quality of life with their long term serviceability and predictable outcomes. Over the years, significant advancements have taken place in the implant systems and the methods of attachments. This paper describes a case report in which a completely edentulous patient was rehabilitated with an implant supported overdenture in mandible and a complete denture in the maxilla.

\section{Reena Luthra, Anuradha Sharma and Palwinder Kaur}

\begin{abstract}
Department of Prosthodontics, Swami Devi Dyal Hospital and Dental College, Panchkula, Haryana, India
\end{abstract}

Corresponding author: Reena Luthra

\section{”harshtanya@yahoo.co.in}

Professor, Department of Prosthodontics, Swami Devi Dyal Hospital and Dental College, Barwala, Dist. Panchkula, Haryana, India.

Tel: +919815998430

\section{Introduction}

The transition from dentulous to edentulous state poses different challenges to the patient as well as the clinician. Bone resorption especially in mandible is an important factor to be considered during rehabilitation. Traditional removable prostheses need continuous adjustments. Implant borne prostheses have proven to be an effective alternative as they have many beneficial effects like preservation of bone volume, improved retention, stability, function, proprioception and comfort.

By placing implants in the edentulous mandible and subsequently loading them, bone resorption can be limited as light irritative stimuli lead to changes in bone architecture, shape and volume resulting in subperiosteal growth [1]. This is supported by Wolff's law, which states that a change in function leads to a change in structure [2]. The reduced degree of rotational freedom of overdenture diminishes the forces applied on the distal part of the mandible while still having mucosal support. Feine and Carlsson advocated the 2-implant retained overdenture as the standard of care for the edentulous mandible in a consensus conference held in 2002 [3-5].

Implant supported overdenture (IOD) is also a cost effective treatment option as compared to implant supported fixed prostheses. They provide facial support, are relatively simple to construct, can restore both dental and alveolar tissues and are esthetically more satisfactory.

Implant supported overdentures vary in design according to the method of attachment and amount of support to be desired from implant and ridge mucosa. The selection of an attachment system whether it is stud, magnet or bar depends on a number of factors such as type of prosthesis, number of implants, patient's expectations, amount of retention required and cost.
Citation: Luthra R, Sharma A, Kaur P. Implant Supported Overdenture: A Case Report. Periodon Prosthodon. 2016, 2:2.

Bar attachment provides superior retention and stability as compared to stud attachments. It also allows splinting of implants and better distribution of forces. Laboratory technician can position attachments parallel to each other even if the implants are not parallel. Incorporating clips on the bar allows vertical movement of denture, thus reducing forces on implants, less screw loosening and less crestal bone loss. Bars can be prefabricated or cast. Due to improved retention and stability of the bars as compared to stud attachments, denture extensions can be kept to the minimum especially in patients with an exaggerated gag reflex.

This case report depicts step by step procedure for fabrication of implant supported over denture with cast bar and clip attachments for an edentulous mandible opposing a maxillary complete denture.

\section{Case Report}

A 60 year old male patient presented to the department of Prosthodontics with multiple missing teeth in maxilla and mandible. Remaining teeth had severe periodontal disease. Patient had no previous experience of any removable denture. Patient was screened according to a protocol that took into account his general health and treatment possibilities. The maxillary ridge 
was favorable for complete denture construction. Preoperative radiographs exhibited severe bone loss and deficiency in height and width in mandible. He was informed about the implantbased treatment strategies that could be followed. After obtaining consent from the patient, it was decided to get all the teeth extracted and replace them with a conventional complete denture in the maxillary arch and a two implant supported overdenture in the mandibular arch. Impressions were made and jaw relations were recorded. Diagnostic teeth setup was done at appropriate vertical dimension to assess the available restorative space for a cast bar and superstructure attached to denture with indirect technique.

\section{Surgical phase}

A surgical guide was fabricated from the diagnostic set up. Four weeks after extraction, two implants (MIS Implants, $3.75 \mathrm{~mm}$ in diameter and $10 \mathrm{~mm}$ in length) were placed at $B$ and $D$ positions following standard protocol [6]. After 2 weeks, patient was given complete dentures. The tissue surface of mandibular denture was relieved and relined using temporary soft denture liner.

\section{Prosthodontic phase}

After 4 months of healing, second stage surgery was carried out and gingival formers were placed (Figure 1). After two weeks, mandibular definitive impressions were made. A custom perforated tray for the mandibular arch was fabricated. Open tray impression copings were attached on the implants. The custom tray was modified to allow individual access to each impression coping.

A rubber base impression was made in polyvinyl siloxane (addition type) (Figure 2). Implant analogs were attached to the impression copings and the impression was poured in die stone.

An autopolymerizing acrylic resin record base was fabricated and stabilized over the gingival formers with the help of light body addition silicone material.

Maxillary cast was mounted on the Hanau's Wide View Articulator with face bow transfer. The mandibular cast was then mounted on the articulator in centric relation. Teeth setting was carried out and tried for patient approval.

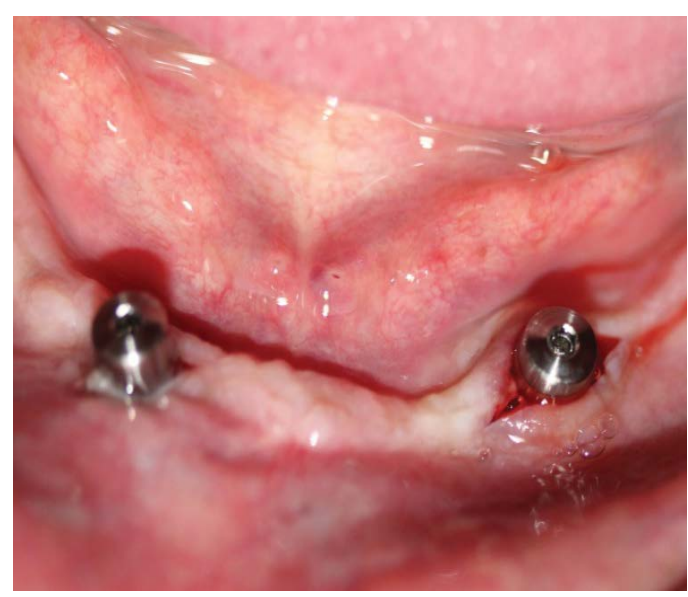

Figure 1
Healing abutments on implants.

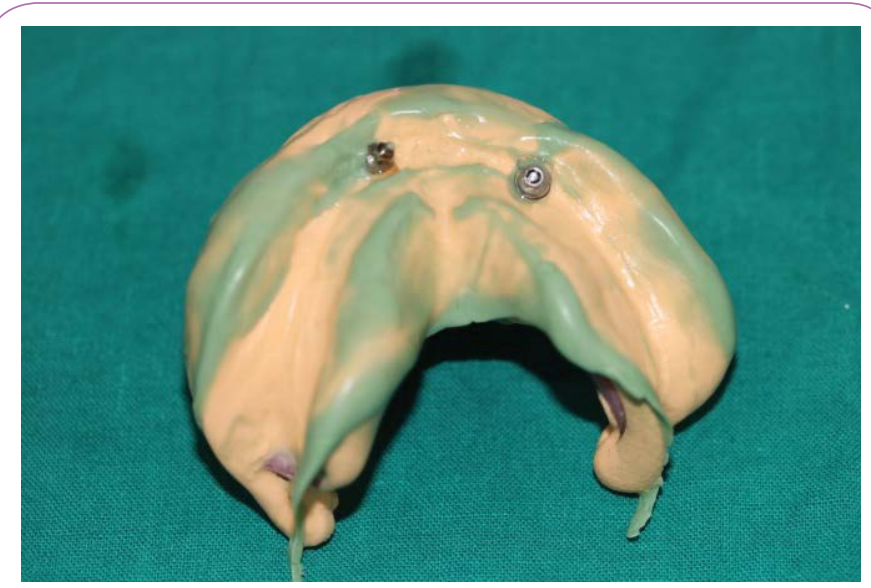

Figure 2 Mandibular final impression.

\section{Bar fabrication}

UCLA abutments were screwed to the implant analogues and cut to appropriate height according to the available restorative space.

A castable bar system (Ceka attachment, PreciLine) was used (Figure 3). The plastic bar pattern was cut to the desired length and attached to the UCLA abutments.

The height of the bar was adjusted to facilitate easy oral hygiene beneath the bar. The bar-abutment pattern assembly was then cast. The bar was finished and polished and checked in patient intraorally and radiographically for passive fit (Figures 4-6).

\section{Fabrication of overdenture}

The finished bar was placed on the articulated master cast. The space was provided for the bar assembly over the tissue surface of the trial denture base. The undercuts were blocked and the whole assembly was duplicated to get the working cast. The trial denture base along with positioner clip and metal housing were placed on the working cast. Care was taken not to disturb the position of the anterior teeth. The undersurface of the metal housing was blocked out with dental stone to avoid flow of resin between clip and bar.

The dentures were processed by conventional technique. The final prosthesis had the metal housings incorporated in the tissue surface. The positioner clips were discarded and yellow retentive clips were used at their place (Figure 7).

\section{Denture insertion appointment}

Finished bar was place in patient's mouth (Figure 8). Abutments were screwed with a final torque of $35 \mathrm{Ncm}$. The screw openings were blocked with gutta percha points. The denture was inserted in the patient's mouth and checked for proper extensions and occlusal contacts.

The retentive clips clicked into place on the bar providing sufficient retention. Instructions were given to the patient regarding the insertion and removal of the denture. 

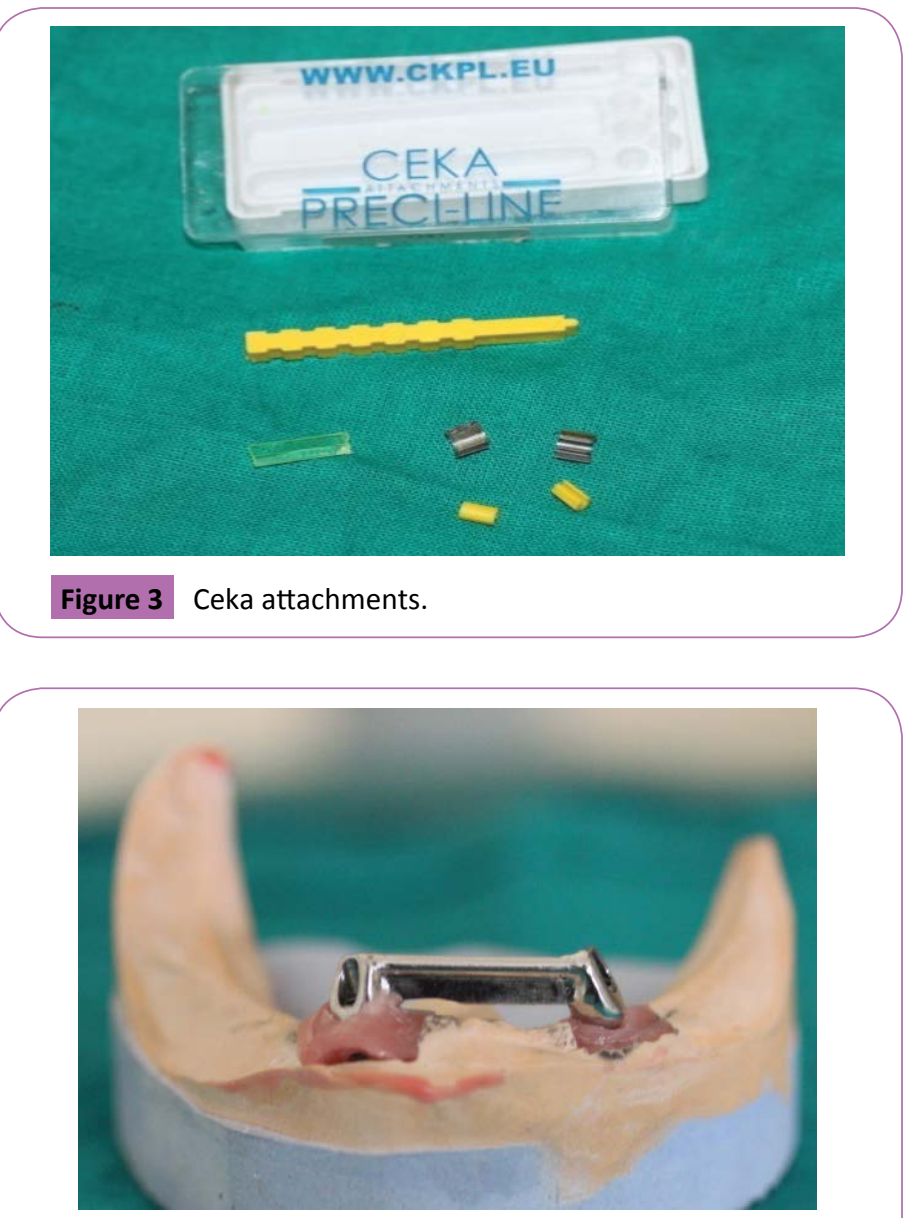

Figure 4 Bar on the master cast.

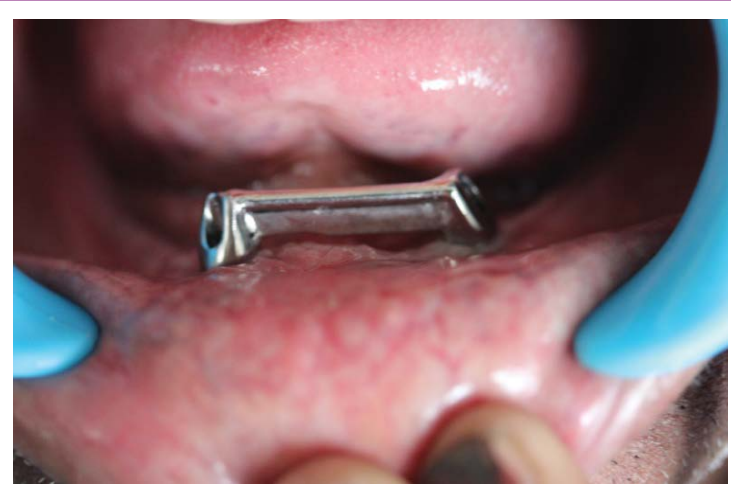

Figure 5 Cast bar intraorally.

\section{Disscusion}

Mandibular anterior region was selected for implant placement as it has sufficient bone in height and width in the interforaminal region. Two implants were planned as literature shows that there is not much difference between the use of 2 implants versus 4 implants for overdentures connected with bars [7]. Splinting of implants with bar was preferred as it has better retention, better load distribution, reduced forces on implants, less screw loosening and crestal bone loss [8]. Wright et al. described a low resorption rate $(0.5 \mathrm{~mm}$ average bone loss) in 21 patients wearing overdentures supported by two implants and a bar in the mandible after a mean period of observation of 5 years [9].

The use of milled bar for anchoring overdentures provide necessary support. The flanges of the overdenture may be utilized to compensate for esthetic and vertical disharmony and to facilitate handling and cleaning of dentures [10].

Chairside technique for clip insertion is difficult to control and is less accurate as it is difficult to block out all the undercuts

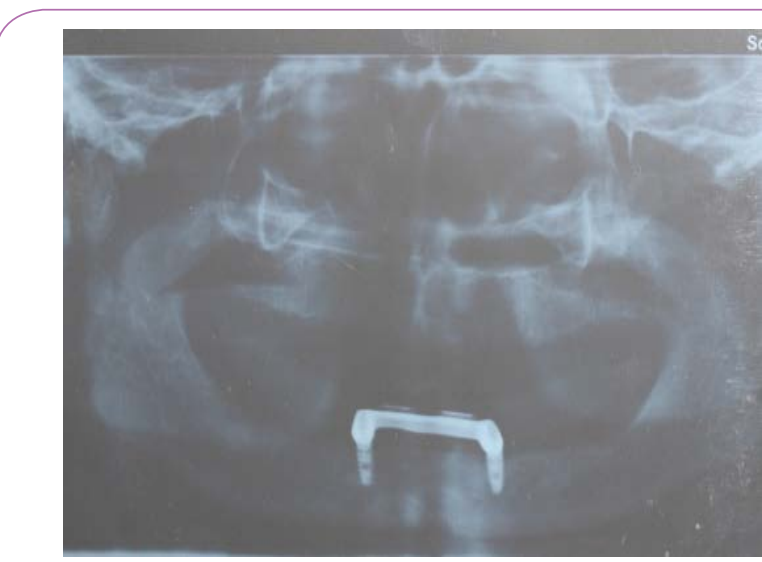

Figure 6 Post-operative OPG with bar screwed to implants.

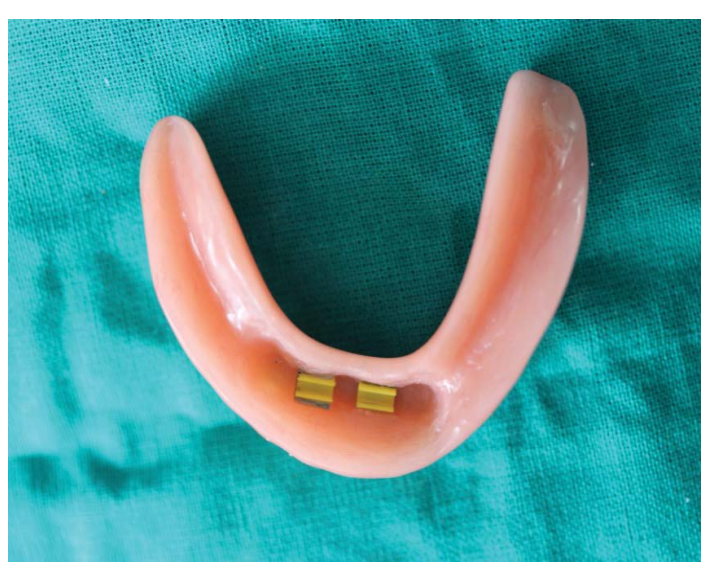

Figure 7 Finished denture.

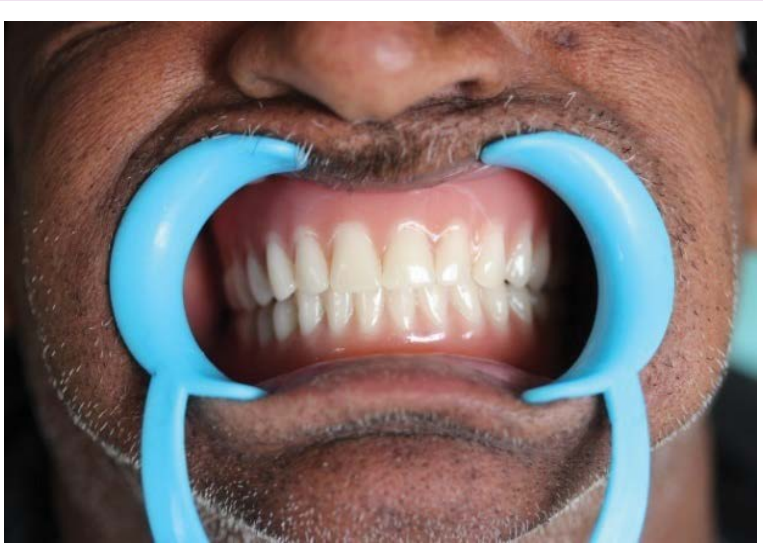

Figure 8 Patient with final prosthesis. 
intraorally. Indirect or laboratory technique was preferred in this case as it causes minimal changes in the final prosthesis during metal clip attachment, allows accuracy of fit, parallel placement of clips and use of heat activated resin to retain the attachments. Two implant supported overdenture with clip attachment also needs less repair $[11,12]$.

The disadvantages of bar retained overdentures are that they are time consuming, expensive, depend heavily on the skills of the laboratory technician and have limited applicability in patients with reduced interarch space.
Inspite of these limitations, implant supported overdentures can be safely considered as the baseline treatment option for the rehabilitation of complete mandibular edentulism.

\section{Conclusion}

This clinical report described the successful management of edentulous patient with implant supported overdentures with cast bar and clip attachment with indirect laboratory technique. It can become an excellent and profitable addition to every prosthodontic practice. 


\section{References}

1 Mosnegutu A, Wismeijer D, Geraets W (2015) Implant-supported mandibular overdentures can minimize mandibular bone resorption in edentulous patients: Results of a long-term radiologic evaluation. Int J Oral Maxillofac Implants 30: 1378-1386.

2 Taylor TD (1989) Osteogenesis of the mandible associated with implant reconstruction: A patient report. Int J Oral Maxillofac Implants 4: 227-231.

3 Feine J, Carlsson G, Awad M, Chehade A, Duncan W, et al. (2002) The McGill consensus statement on overdentures. Mandibular twoimplant overdentures as first choice standard of care for edentulous patients. Gerodontology 19: 3-4.

4 Feine J, Carlsson G (2003) Implant overdentures: The standard of care for edentulous patients. Chicago: Quintessence Publishing Co., pp: 155-157.

5 Geckili O, Cilingir A, Erdogan O, Kesoglu AC, Bilmenoglu C, et al. (2015) The influence of momentary retention forces on patient satisfaction and quality of life of two-implant-retained mandibular overdenture wearers. Int J Oral Maxillofac Implants 30: 397-402.

6 Misch CE (2005) Treatment options for mandibular implant overdentures: An organized approach. Dental Implant Prosthetics. Elsevier Mosby Publication, pp: 206-227.
7 Krennmair G, Krainhofner M, Piehslinger E (2007) Implant-supported mandibular overdentures retained with a milled bar: A Retrospective Study. Int J Oral Maxillofac Implants 22: 987-994.

8 Akca K, Akkocaoglu M, Comert A, Tekdemir I, Cehreli MC (2015) Bone strains around immediately loaded implants supporting mandibular overdentures in human cadavers. Int J Oral Maxillofac Implants 30: 397-402.

9 Wright PS, Glantz PO, Randow K, Watson RM (2002) The effects of fixed and removable implant-stabilised prostheses on posterior mandibular ridge resorption. Clin Oral Implants Res 22: 315-321.

10 Sadowsky SJ (2001) Mandibular implant-retained overdentures: A literature review. J Prosthet Dent 86: 468-473.

11 Visser A, Raghoebar GM, Meijer HJ, Batenburg RH, Vissink A (2005) Mandibular overdenture supported by two or four endosseous implants. A 5-year prospective study. Clin Oral Implants Res 16: 19-25.

12 Batenburg RH, Raghoebar GM, van Oort RP, Heijdenrijk K, Boering G (1998) Mandibular overdenture supported by two or four endosseous implants. A prospective comparative study. Int J Oral Maxillofac Surg 27: 435-439. 